\title{
CONHECIMENTO PROPOSICIONAL NAS AULAS DE FILOSOFIA NO ENSINO MÉDIO: ENTRE A DIDÁTICA E O ENSINO
}

\author{
PROPOSITIONAL KNOWLEDGE IN HIGH SCHOOL PHILOSOPHY CLASSES: \\ BETWEEN DIDACTIC AND TEACHING
}

\author{
Jean C. Caldas ${ }^{1}$
}

\section{RESUMO}

Neste artigo eu defendo que o conhecimento de proposições filosóficas pode e deve desempenhar o papel de ideal regulador das aulas de Filosofia no Ensino Médio. Grosso modo, penso haver dois tipos de conhecimento pressupostos nas aulas de Filosofia no Ensino Médio: o primeiro, que, por conveniência, chamarei de conhecimento filosófico disposicional, e o segundo, o conhecimento filosófico proposicional. O primeiro consiste naquele conhecimento que leva em conta apenas certas habilidades filosóficas de identificação de teses, de identificação e análise de argumentos etc. O segundo envolve a garantia da verdade de uma proposição filosófica via justificação. Argumento que o conhecimento filosófico disposicional, embora seja um pressuposto epistemológico suficiente a ser tomado para a confecção de uma aula de Filosofia no Ensino Médio, não é necessário. Isso porque esse tipo de conhecimento não desempenha satisfatoriamente a função de objetivo último das aulas de Filosofia, se considerarmos uma característica fundamental da Filosofia: qual seja, aquela atividade que, através de seus autores, possui enquanto objetivo último obter conhecimento de certas proposições filosóficas. Além disso, argumento que o primeiro tipo de conhecimento é adequadamente desenvolvido somente se regulado por um ideal de conhecimento do segundo tipo. Assim considerado, além de fazermos, de fato, a Filosofia presente na sala de aula, tendemos a ter ganhos consideráveis para a postura dos alunos frente às questões filosóficas fundamentais.

Palavras-chave: ensino de filosofia; conhecimento proposicional; BNCC.

\section{ABSTRACT}

In this paper, I argue that knowledge of philosophical propositions can and should perform a role as regulative ideal in high school philosophy classes. Roughly speaking, I think that there are two kinds of knowledge assumed in high school philosophy classes: the first, which, for convenience, I shall call philosophical dispositional knowledge, and the philosophical propositional knowledge. The first one consists in the knowledge that takes into account only certain philosophical skills such as thesis identification, argument identification etc. The second one involves the guarantee of the truth of a philosophical proposition through justification. I argue that the philosophical dispositional knowledge, although it is a sufficient epistemological presupposition to be assumed for the preparation of high school philosophy classes, it is not necessary. This is because this kind of knowledge does not sufficiently plays a role as the ultimate goal in philosophy classes, if we consider that Philosophy itself,

1 Ex-residente do Subprojeto Artes, Filosofia, Sociologia, do Programa Institucional Residência Pedagógica - CAPES, pela Universidade Federal do Rio Grande do Sul, é licenciado em Filosofia pela mesma universidade, e mestrando no Programa de Pós-Graduação em Filosofia da mesma universidade. E-mail: caldascaiaffo@gmail.com. 
Thaumazein, Ano IX, v. 13, n. 25, Santa Maria, p. 47-56, 2020.

by its authors, has the philosophical propositional knowledge as an ultimate goal. Further, I argue that the first kind of knowledge is properly understood only if it is regulated by the second kind of knowledge ideal. Thus considered, besides the fact that, in this way, we in fact make Philosophy present itself in high school classes, we will have considerable gains for the students' posture in face of the fundamental philosophical problems.

Keywords: philosophy teaching; propositional knowledge; BNCC;

\section{INTRODUÇÃO}

Sempre pressupomos um certo tipo de conhecimento a ser alcançado pelos alunos a partir das nossas aulas de Filosofia no Ensino Médio. O tipo de conhecimento, evidentemente, deve abarcar características fundamentais da atividade filosófica. É corrente e razoável compreender a atividade filosófica como sendo uma atividade eminentemente analítica, e por isso, que pressupõe a disposição de certas habilidades como as de identificação e elaboração de teses, análise e confecção de argumentos etc. Assim compreendida, estamos justificados a acatar um ensino de Filosofia no Ensino Médio que esteja em total conformidade com os parâmetros gerais estabelecidos pela Base Nacional Comum Curricular $(B N C C)^{2}$, a qual delimita os objetivos epistêmicos enquanto habilidades e competências (no nosso caso, poderíamos dizer, filosóficas); em outras palavras, um tipo de conhecimento que chamarei aqui de conhecimento filosófico "disposicional". Contudo, se considerados os aspectos fundamentais da Filosofia, tais objetivos mereceriam ser compreendidos como últimos ou supremos, de tal sorte que deveríamos levar em conta apenas tais habilidades quando da elaboração e realização dos nossos planos de aula? Antes disso: tomar enquanto objetivo epistêmico supremo das aulas de Filosofia no Ensino Médio a disposição, por parte dos alunos, de certas habilidades argumentativas é mesmo necessário para uma aula de Filosofia?

Meu objetivo nesse texto é sugerir uma delimitação dos objetivos epistêmicos das aulas de Filosofia no Ensino Médio, resgatando a noção clássica de conhecimento proposicional. Em verdade, sugerirei que, se queremos que a Filosofia esteja de fato presente na sala de aula, os objetivos devem ser competências e habilidades filosóficas reguladas pelo ideal de conhecimento filosófico proposicional. Esse objetivo será realizado mediante: (i) uma descrição e avaliação geral de pressupostos epistemológicos correntes nas aulas de Filosofia que privilegiam um conhecimento filosófico disposicional; e (ii) uma caracterização da Filosofia a partir da qual podemos extrair a ideia de que não devemos levar em conta apenas um conhecimento filosófico disposicional nas suas aulas no Ensino Médio, mas, também, o conhecimento filosófico proposicional. Mas, de antemão, gostaria de advertir que meu ponto é muito mais tecer considerações acerca da intersecção entre a didática e o ensino de Filosofia sob essa perspectiva do que argumentar fortemente a respeito disso tudo: quero mostrar algo que pode estar entre a didática e o ensino de Filosofia, a qual pressupõe o conhecimento proposicional enquanto ideal regulador. Isso esclarecerei na parte conclusiva deste texto, e aproveitarei para ilustrar com algumas considerações práticas sobre a minha experiência através do Programa Residência Pedagógica.

2 BRASIL. Base Nacional Comum Curricular. Brasília: MEC, 2017. 
Thaumazein, Ano IX, v. 13, n. 25, Santa Maria, p. 47-56, 2020.

\section{PRESSUPOSTOS EPISTEMOLÓGICOS CORRENTES NAS AULAS DE FILOSOFIA: O CONHECIMENTO FILOSÓFICO DISPOSICIONAL}

Inicialmente, vamos delinear a noção de conhecimento filosófico disposicional enquanto objetivo epistêmico das aulas de Filosofia no Ensino Médio. Tomemos, grosso modo, os procedimentos correntes utilizados, considerando o que chamarei de registros das aulas de Filosofia. Consideremos o primeiro. Se preparamos um plano de aulas sobre, por exemplo, a natureza da realidade segundo Aristóteles e Descartes, então podemos estabelecer se queremos que os alunos saibam distinguir as teses de Aristóteles das teses de Descartes a respeito da estrutura fundamental do mundo; isto é, os significados distintos do termo substância defendidos por eles. Em particular, talvez, queremos que os alunos saibam distinguir a ideia de acordo com a qual a substância primeira - aquilo que poderíamos dizer que é o que há de mais real na realidade -, segundo Aristóteles, possui basicamente duas características, a de suporte de propriedades, e a de sempre ser sujeito das predicações, da ideia de que segundo Descartes, a substância, além de ser substrato de propriedades, possui também a característica de ser causa de si mesma. Se optarmos por isso, a exposição dessas duas visões acerca da natureza da realidade pode ser resumida a uma apresentação dos dois conjuntos de teses, com vistas a mostrar aos alunos o que Aristóteles e Descartes entendiam como sendo a natureza do mundo. É um procedimento que se reduz ao registro tético. Grosso modo, se assim se resume, então tomamos como objetivo epistêmico dessas aulas uma espécie de conhecimento disposicional porque relacionado a certas habilidades de identificação e distinção das teses desses filósofos. É um saber identificar a distinguir teses distintas.

De outra maneira, poderíamos pensar em uma aula acerca desse mesmo tema, porém em um registro problemático. Assim, partiríamos, por exemplo, da questão "o que há de mais real na realidade?". Talvez, na melhor das hipóteses, começaríamos analisando a questão - os seus termos, o que é requerida por ela. Partindo disso, exporíamos as respostas dos filósofos a essa questão. Se assim fazemos, então essa aula, embora se dêa partir de um registro problemático, permaneceria, no final das contas, no âmbito tético: uma apresentação das teses dos filósofos, as quais desempenhariam o papel de resposta a essa problemática e, na melhor das hipóteses, exporíamos seus argumentos. Embora mudássemos levemente de perspectiva em relação ao primeiro registro, ainda estaríamos pressupondo um conhecimento filosófico disposicional: a análise do problema, a identificação de hipóteses dos filósofos que respondem a determinados problemas filosóficos fundamentais etc.; um saber aplicar certas ferramentas filosóficas fundamentais.

Há também o que poderíamos chamar de registro analítico de uma aula de Filosofia, isto é, o da análise dos argumentos dos filósofos acerca de temas, conceitos, problemas. Esse registro se restringiria a uma análise lógica dos argumentos envolvidos. Em particular, poderíamos expor os argumentos de Aristóteles e de Descartes com relação à estrutura da realidade, e verificar as relações de suas premissas com a conclusão (a qual representa sua tese), a relação lógica entre as premissas etc.. Isso pressuporia claramente, também, o conhecimento envolvido naquelas habilidades; portanto, disposicional: em particular, o reconhecimento de conectivos lógicos, do valor de verdade das proposições envolvidas e, forçando um pouco a barra, realizar cálculos proposicionais para verificar a validade do argumento etc.

É claro que podemos pensar em um registro misto - o qual, creio, é o mais comum e razoável sob o ponto de vista das formas de desenvolvimento de tais habilidades - o qual envolve os três registros 
expostos acima em uma aula só ou em uma mesma proposta didática. É claro, a meu ver, que se tem um ganho extraordinário quando as aulas são pensadas assim, ainda que esteja em jogo, fundamentalmente, um conhecimento filosófico disposicional; um saber fazer, nesse caso, conjugado.

Alguém poderia sustentar que o conhecimento filosófico disposicional envolvido nas aulas que levam em conta esses registros acima delineados não é suficiente para dizer que elas são, propriamente, aulas de Filosofia. Contudo, creio que as razões para sustentar isso são fracas. De fato, o que está em jogo neste que eu chamo de conhecimento filosófico disposicional é suficiente para dizermos que é uma atividade filosófica, dados seus "objetos" e a sua abordagem via ferramentas filosóficas com as quais mobilizaríamos as teses, problemas e argumentos dos filósofos e/ou suas correntes em aulas de Filosofia. Isso, trivialmente, de maneira nenhuma fugiria do escopo da Filosofia tal como a entendemos - e que, de fato, muito realizamos nos centros universitários. Isso tudo é suficiente para caracterizar, adequadamente, aulas de Filosofia.

O que desejo salientar é que não importa o tipo de procedimento adotado em uma aula de Filosofia no Ensino Médio ou o registro que escolhemos para ela: se estamos comprometidos com ela, então estaremos - considerando as melhores hipóteses - pressupondo um tipo de conhecimento que almejamos ser desenvolvido através das nossas aulas. E o que usualmente é pressuposto é um conhecimento disposicional. O problema que quero colocar, contudo, é se os procedimentos que levam em conta somente certo conhecimento disposicional são tudo o que podemos fazer na sala de aula. Seriam esses procedimentos necessários para abarcar a Filosofia que pode estar presente nas aulas de Ensino Médio? Quero questionar, também, se é razoável apenas esses procedimentos estarem presentes ali, se aceitarmos certa caracterização da Filosofia e certa motivação para que a Filosofia seja interna ao aluno, as quais pretendo sugerir na sequência.

\section{A FILOSOFIA DOS FILÓSOFOS E A FILOSOFIA NA SALA DE AULA}

Agora, vamos dar um passo atrás, e verificar se o conhecimento filosófico disposicional pressuposto em uma aula é, além de suficiente, necessário para uma aula de Filosofia no Ensino Médio. Aqui, sugerirei uma caracterização da Filosofia, a qual, a meu ver, nos guia para uma caracterização do que penso que devem ser os pressupostos epistemológicos da Filosofia no Ensino Médio.

Uma característica comum entre os quatro registros apresentados anteriormente é a ideia de que o aluno tem de ter uma experiência da Filosofia nas aulas; isto é, "experienciar" as teorias dos filósofos. Uma atividade de exame de suas teorias - através de todas as habilidades que venho mencionando pode ser compreendida como a experiência de um objeto dado, qual seja, a Filosofia feita por filósofos. Nesse caso, o objetivo consistiria em saber quais são, por exemplo, as teses de Aristóteles e/ou Descartes acerca de determinado tema, como eles argumentaram, quais são os problemas que eles buscaram responder, se suas ideias se seguem de seus pressupostos etc. Experienciar desse modo a Filosofia feita pelos filósofos de fato é algo importante para uma aula de Filosofia do Ensino Médio - e, é claro, não só no Ensino Médio. Mas é só isso o que podemos fazer?

Penso que, a partir desses registros possíveis, a Filosofia se mostra enquanto algo externo ao aluno; isto é, ela vem a ser um "conhecimento preexistente" com relação ao qual o aluno desempenharia 
certas habilidades com intuito último de compreensão da Filosofia feita por filósofos. É como se fosse um museu das ideias, com o qual os alunos deveriam entrar em contato munidos de certas ferramentas para ter das peças expostas uma boa experiência. No entanto, alguém poderia razoavelmente dizer que ela poderia muito bem ser interna ao aluno na medida em que ele devesse produzir teses filosóficas a respeito de um tema a partir de suas habilidades filosóficas e não apenas apreciar as teses e argumentos alheios. É claro que todos os alunos terão suas teses com relação a seja o que for; adolescentes são furiosamente opinativos. Mas aquilo a que estou me referindo são teses justificadas: melhor dizendo, crenças justificadas a respeito de assuntos filosóficos - isso é distinto de suas crenças justificadas a respeito da teoria de algum filósofo estudada em aula. Essas crenças podem ser a respeito de temas como a estrutura da realidade, a natureza da liberdade, a natureza do belo, do modo pelo qual se deve viver etc.. Aqui chegamos a um ponto crucial, e que de fato foi a alavanca para identificar uma possibilidade de aula que tanto pudesse abarcar aspectos fundamentais da Filosofia, no que diz respeito aos seus objetivos, como também, e por causa disso, tentar achar um caminho para despertar o desejo dos alunos por conhecer - algo que devemos levar seriamente em consideração ${ }^{3}$.

A Filosofia existe na sala de aula somente se ela é interna ao aluno. Essa internalização da Filosofia é realizada, como acabei de dizer, ao depositar no aluno a prerrogativa de justificar suas crenças com relação a determinados temas filosóficos. No entanto, em particular, se ele crê que é livre, então ele deve justificar tal crença, de tal sorte que mostre ou garanta filosoficamente a verdade de sua crença. É evidente que habilidades relacionadas ao argumentar são fundamentais aqui; afinal, para justificar uma crença é necessário um conjunto de razões logicamente conectadas que satisfaçam o princípio do argumento correto (em oposição a um argumento meramente válido). Assim sendo, o ponto a que quero chegar é o seguinte: visto que justificar pressupõe uma boa argumentação, e se bem argumentar é fazer com que as premissas garantam a verdade da conclusão, então justificar é garantir a verdade de sua crença. Assim considerado, tomando essa concepção "teleológica" da argumentação e da justificação - segundo a qual a justificação visa, ou tem de visar estabelecer uma crença verdadeira -, considerando a ideia de que a Filosofia deve ser interna ao aluno no sentido acima descrito, e considerando que uma das coisas que os alunos devem saber fazer é bem argumentar, então o que esperamos dos alunos é que eles, em última análise, devam ter conhecimento acerca de determinadas proposições filosóficas nas quais eles acreditam4.

É nesse preciso sentido em que penso que a Filosofia existe na sala de aula de Ensino Médio somente se ela é interna ao aluno: a Filosofia não é uma atividade somente de argumentação e ponto final; aquilo que conhecemos de "produtos" da Filosofia por aí são certas argumentações que visam, em última análise, garantir a verdade de determinadas proposições filosóficas; seus autores e autoras buscaram ter conhecimento acerca de certas proposições. Ora, certamente temos de ter em mente tais produtos

3 Falarei sobre isso na seção conclusiva deste artigo.

4 Aquilo a que estou me referindo com "conhecimento proposicional" equivale a sua definição tradicional: crença verdadeira justificada. E isso é correntemente traduzido em um esquema geral do conhecimento que consiste: $S$ sabe que P sse (i) S crê que P; (ii) P é verdadeiro; e (iii) S crê que P porque P é verdadeiro. Tal condição (iii) do esquema tem sido interpretada de diferentes maneiras. Mas, devido ao objetivo desse texto, não estou pressupondo nenhuma interpretação específica; isso não é relevante aqui. O ponto que sugiro aqui é que um cenário ideal que deve justificar os objetivos imediatos das aulas de Filosofia no Ensino Médio é o cenário em que o sujeito S, segundo esse esquema, seja substituído pelo aluno A; e P consista, nesse caso, em uma proposição filosófica - isto é, uma proposição cujo conteúdo seja ligado aos problemas fiosóficos. 
almejados pelos seus autores e autoras. Contudo, é claro que podemos pensar que a finalidade da atividade filosófica é a de simplesmente dizer para onde não devemos ir se queremos conhecer; isto é, utilizando um certo jargão, filósofos "limpam o terreno" para a possibilidade do conhecimento. Mas, ainda assim, o ponto é que o que a Filosofia busca é conhecer as coisas que competem a ela conhecer; e não simplesmente argumentar independentemente de garantir ou não a verdade de determinadas proposições. Isso é parte constituinte fundamental da Filosofia. Assim, considero que, se a Filosofia existe na sala de aula, então ela é interna ao aluno; e, se é interna ao aluno, então o aluno argumenta com vistas a garantir a verdade de suas crenças.

Desse modo considerada, a Filosofia deixa de ser, na sala de aula, um objeto externo do qual o aluno deve ter uma experiência, e as aulas passam a propiciar uma experiência do aluno com a Filosofia. Essa experiência se caracteriza por uma atividade de justificação com vistas ao conhecimento proposicional. Disso podemos extrair que o objetivo ou meta epistêmica fundamental dessas aulas deve ser que o aluno $A$ creia que $P$, que $P$ seja verdadeiro, e que $A$ justifique que $P$ é verdadeiro.

\section{CONHECIMENTO FILOSÓFICO PROPOSICIONAL ENQUANTO IDEAL REGULADOR}

A ideia de conhecimento filosófico proposicional enquanto objetivo ou meta das aulas de Filosofia no Ensino Médio é sujeita a boas críticas. Uma delas é a crítica quanto a sua aplicabilidade: seria ingênuo acreditar que alunos de Ensino Médio venham a possuir crenças verdadeiras e justificadas a respeito, por exemplo, da estrutura da realidade; muito mais ingênuo seria pensar que eles podem justificar a verdade de proposições acerca do modo pelo qual se deve viver. Há implicações aqui importantes as quais dizem respeito aos limites do estado da capacidade cognitiva dos alunos, e a respeito de determinados objetos da Filosofia. Parece-me claro que não podemos pressupor que o aluno desenvolva uma teoria metafísica acabada durante um trimestre de aulas que garanta, em particular, que a realidade se constitui fundamentalmente de objetos de tipo $x$ - digamos, em particular, de corpos simples e duros, como no caso de alguns empiristas, ou substrato de propriedades, para os filósofos de outras correntes; ou mesmo que garanta que não é possível conhecer a estrutura da realidade. Trivialmente também não teríamos boas razões para tomar como objetivo das nossas aulas que os alunos obtenham conhecimento acerca do modo pelo qual se deve viver.

As críticas mencionadas acima são, a meu ver, trivialmente legítimas. Assim sendo, dadas as caracterizações da Filosofia e da justificação acima desenvolvidas, e dadas essas considerações acerca da ideia de tomar o conhecimento proposicional enquanto objetivo/meta das aulas de Filosofia no Ensino Médio, creio que é muito mais adequado pensarmos no conhecimento proposicional enquanto o ideal dessas aulas. Mas um ideal compreendido de uma maneira: ideal regulador. Mas, o que significa ser um ideal regulador?

A ideia de ideal regulador que pretendo lançar mão aqui consiste num conceito equivalente ao conceito de ideal que Immanuel Kant caracteriza no terceiro capítulo do segundo livro da Dialética Transcendental, na Crítica da Razão Pura5. Ali, o filósofo sugere uma identificação de "ideal" como um "princípio (prático) regulador", isto é, um princípio que possui uma função reguladora das ações. Vejamos o que ele nos diz:

5 Cf. A 569-571/B; 597-599. 
Thaumazein, Ano IX, v. 13, n. 25, Santa Maria, p. 47-56, 2020.

[...] a razão humana contém não só ideias, mas também ideais os quais, embora não possuam força criadora como os ideais Platônicos têm, no entanto, possuem força prática (como princípios reguladores), fundamentando a possibilidade de perfeição de certas ações. [...] A virtude, e com ela a sabedoria humana em toda a sua pureza, são ideias. Mas o sábio (dos Estoicos) é um ideal, i.e., um homem que existe meramente no pensamento, mas o qual é inteiramente congruente com a ideia de sabedoria. Portanto, assim como a ideia dá a regra, assim o ideal, em casos como esse, serve de arquétipo para a determinação completa da cópia; e não temos outro modelo das nossas ações senão a conduta deste homem divino em nós, com o qual podemos nos comparar, nos julgando e, assim, nos aperfeiçoando, ainda que nunca possamos alcançar tal modelo (A 569-571/ B 597 - 599).

Embora Kant esteja, evidentemente, preocupado com outras coisas ao escrever tal caracterização do conceito de ideal, podemos muito bem, creio, usá-la em parte para o nosso propósito. Um ideal, nesse sentido, funciona praticamente, e possui um caráter de arquétipo ou protótipo; não obstante, está no pensamento. Ora, dessas características, extraímos a ideia de que um ideal é uma representação de um estado de coisas perfeito que regula a nossa prática dada a natureza daquilo que é representado, qual seja, a sua perfeição. De antemão estaríamos dispostos a pensar que, pela sua natureza, ele simplesmente é uma mera quimera ou utopia. Tendo em vista isso, retomemos a caracterização kantiana:

Esses ideais, ainda que ninguém possa a eles conceder realidade objetiva (existência), não devem ser compreendidos, no entanto, enquanto meras quimeras; ao invés disso, eles provêm um modelo indispensável para a razão, o qual precisa do conceito daquilo que é inteiramente completo em sua espécie, para então acessar e medir o grau e os defeitos daquilo que é imperfeito (loc.cit.).

Desse conjunto de afirmações, extraímos a ideia de que o ideal não é factível - i.e., não existe e não pode existir por aí enquanto tal -, mas possui um valor normativo a partir do qual podemos representar a imperfeição dos objetos/estado de coisas imperfeitos enquanto imperfeitos. Assim, se ele possui uma função prática, então tal normatividade se aplica às nossas ações, como um guia das ações com vistas à aproximação deste arquétipo. E é porque ele possui tal normatividade que somos capazes de agir levando-o em conta.

Grosso modo, é mais ou menos assim que penso o conhecimento filosófico proposicional enquanto ideal regulador das aulas de Filosofia no Ensino Médio: algo que constitui o objetivo supremo das aulas, cuja posse, por parte dos alunos, é o que regula as aulas. E, assim, sendo ele tal ideal regulador, ele deve ser aquilo que dá valor e sentido às atividades que realizamos nas aulas - atividades essas que representam aquilo a que me referi ao falar de um conhecimento filosófico disposicional. O fato de o conhecimento proposicional colocar sentido e valor nas habilidades e competências porque é o que as regula não me parece ser algo trivial. Pois, é a partir dele que podemos justificar (talvez filosoficamente) o desenvolvimento de competências habilidades específicas: as habilidades de identificação de teses, confecção de teses, identificação de premissas e conclusões são desenvolvidas, em última análise, porque aquilo que almejamos é que os alunos tenham conhecimento proposicional: isto é, que eles acreditem em determinada proposição, que essa proposição seja verdadeira e que eles possuam argumentos/razões que garantem a verdade de 6 Minha tradução a partir da tradução para o inglês da Crítica da Razão Pura. (cf. GUYER, P; WOOD, A; 1998). 
tal proposição. A posse das habilidades não se apresenta, assim, como meras ferramentas para compreensão da Filosofia que filósofos fizeram, mas como ferramentas filosóficas para a filosofia que os alunos devem fazer. E, enfatizo, assim a Filosofia se torna interna ao aluno; e dada a caracterização da Filosofia sugerida, assim a Filosofia estaria completamente presente na sala de aula.

Desse modo, sugiro que o conhecimento filosófico disposicional que é pressuposto naqueles registros de aulas acima delimitados, por mais importante que seja para a atividade filosófica na sala de aula, deve ser compreendido como instrumental. Em particular: saber identificar a tese $T$ do filósofo $F$ a respeito do problema/tema $P$, saber identificar os argumentos do filósofo $F$ que sustenta a tese $T$ acerca do problema/tema $P$, etc., não deve consistir naquilo que guia o conjunto das aulas da disciplina. O conhecimento envolvido em tais registros deve ser compreendido como meio para que o aluno conheça. É a partir da clareza, por parte do aluno, do ideal regulador da atividade filosófica realizada em sala de aula - o conhecimento filosófico proposicional - que ele terá excelentes razões para dispor de tais ferramentas.

\section{CONCLUSÃO}

O que busquei sugerir aqui é a razoabilidade de considerarmos as aulas de Filosofia no Ensino Médio como possuidoras de pressupostos epistemológicos de competências e habilidades filosóficas (aquilo que, em geral está pressuposto na BNCC) regulados pelo ideal de conhecimento de proposições filosóficas. Tentei mostrar que, muito embora usualmente pressuponhamos as competências e habilidades filosóficas como objetivos das aulas de Filosofia consoante a determinados registros, podemos - e, se aceitarmos a caracterização da Filosofia aqui dada e a importância da internalização da Filosofia, devemos - tomar como o ideal regulador a aquisição, por parte dos alunos, de conhecimento proposicional acerca de determinadas respostas à determinada problemática filosófica fundamental. Assim tomado, o conhecimento filosófico proposicional é o que normatiza o desenvolvimento de certas habilidades e competências na justa medida em que é um ideal a ser alcançado através da prática em sala de aula. Ainda que seja um ideal nesse sentido kantiano, é a condição pela qual a Filosofia necessariamente está na sala de aula.

A partir disso, e a partir da caracterização das aulas como tendo esses pressupostos, creio que podemos olhar para esse ideal como estando entre o ensino e a didática da Filosofia no Ensino Médio. Por um lado, damos sentido e valor às competências e habilidades, na medida em que as tomamos como meios para tal ideal. Em um certo sentido, é claro que devemos ensinar os critérios para um bom uso de ferramentas filosóficas para a boa argumentação, assim como um médico deve nos apontar como devemos levar a vida para ter uma vida saudável. Certamente, em boa medida, é isso que devemos fazer no Ensino Médio. Não obstante, o caso em que o aluno sabe usar tais ferramentas, usa essas ferramentas, mas não tem claro que o objetivo último é a posse de conhecimento filosófico proposicional, me parece ser análogo ao caso de fazer tudo aquilo que o médico nos prescreveu, ter uma vida saudável, mas não ter a clareza de que a saúde serve para outro objetivo mais robusto, como a plena realização dos nossos projetos de vida. Por outro lado, devemos dar, enquanto professores, grande primazia a uma estratégia didática com vistas ao desenvolvimento de um compromisso filosófico dos alunos: um compromisso pela 
busca de crenças verdadeiras justificadas, e não pela "mera" argumentação. Despertar certa "angústia filosófica" por conhecer as repostas às questões fundamentais da humanidade vale muito mais, segundo essa perspectiva, do que somente auxiliá-los a utilizar ferramentas filosóficas para compreender a Filosofia dos filósofos.

Permita-me finalizar com uma breve consideração que diz respeito a um caso específico que presenciei na minha prática através do Programa Residência Pedagógica, e que de fato me motivou a pensar os pressupostos epistemológicos das aulas de Filosofia no Ensino médio dessa maneira. No início do ano letivo aplicamos um questionário aos alunos para sondar algumas intuições sobre, em particular, o que seria uma boa aula. Uma resposta de uma aluna de uma turma para a qual eu daria aula chamou muito a minha atenção: segundo ela, uma boa aula é aquela em que, entre outras coisas, o professor mostra as razões pelas quais os alunos devem estudar aquilo que o professor diz que eles devem estudar. Essa ideia me pareceu e me parece muito valiosa. É claro que poderíamos mostrar as razões pelas quais os alunos devem estudar aquilo que solicitamos apelando para certos documentos que estabelecem os parâmetros curriculares, ou mesmo o próprio plano de ensino estabelecido por nós. No entanto, é claro que não era isso que a aluna considerava relevante enquanto razão. As razões pelas quais os alunos devem estudar certos assuntos filosóficos podem ser fundamentadas por alguma razão fundamental, algum objetivo fundamental. Nesse sentido, desde então, a cada plano de ensino e aula confeccionada, perguntava a mim mesmo a respeito da justificação de tais habilidades filosóficas que buscava desenvolver com os alunos. É claro que tais habilidades possuem um valor intrínseco; mas o ponto seria esclarecer se haveria alguma finalidade a serem atribuídas a elas; e a sua relação com a Filosofia que os filósofos fazem. Foi a partir daí que comecei a elaborar tal ideia de conhecimento filosófico proposicional enquanto ideal regulador: há uma razão fundamental pela qual devemos fazer com que os alunos desenvolvam habilidades filosóficas, e ela tem de ser considerada o conhecimento de proposições filosóficas, de respostas aos problemas filosóficos fundamentais - e não meramente informações a respeito dos pensamentos filosóficos de determinados autores, aquilo que chamei de compreensão da "filosofia dos filósofos".

Logo depois que adotei tal perspectiva em termos didáticos, e que esclareci aos alunos o nosso ideal, foi perceptível o assentimento de um certo compromisso pela investigação de respostas verdadeiras aos problemas fundamentais. Afinal, eles teriam de argumentar com vistas ao estabelecimento da verdade de suas ideias, com relação aos problemas fundamentais, com o auxílio dos filósofos através de suas teorias, e do professor enquanto intermediário entre eles e os filósofos. É claro que não realizamos o ideal; afinal, é um ideal. Mas a postura foi fundamentalmente modificada, na medida em que o sentido das atividades se tornou evidente e muito mais robusto, e os alunos foram instigados a desempenharem uma função mais ativa nas atividades. Em uma aula de introdução à filosofia moral de Aristóteles, no segundo trimestre do ano letivo - após o esclarecimento da empreitada -, sem entrar em qualquer detalhe acerca das definições e argumentações do filósofo, mas apontando para a ideia de que, segundo ele, devemos viver em busca de uma vida boa, uma aluna pergunta: por que eu deveria viver em busca de uma vida boa se eu não sei o que é uma vida boa? A questão certamente permanece; mas não como antes. ${ }^{7}$

7 Agradeço fortemente aos colegas Márcia Laux e Thiago Gruner pelas considerações tecidas acerca dessas hipóteses; à professora Dra. Mitieli Seixas pela organização do Encontro Regional do Residência Pedagógica e pelas suas observações 
Thaumazein, Ano IX, v. 13, n. 25, Santa Maria, p. 47-56, 2020.

\section{REFERÊNCIAS}

BRASIL. Base Nacional Comum Curricular. Brasília: MEC, 2017.

KANT, I. Critique of Pure Reason. GUYER, P; WOOD, W. A. (trad.). Cambridge: Cambridge University Press, 1998.

acerca da versão preliminar deste trabalho; e, claro, à coordenadora do subprojeto Filosofia do Programa Residência Pedagógica da UFRGS, a professora Dra. Priscilla Spinelli, pelos excelentes comentários, críticas e observações sobre a primeira versão deste artigo. Embora eles não sejam culpados por essas ideias que escrevi aqui, eles certamente são responsáveis por terem deixado a minha experiência nesse Programa muito mais gratificante. 